\title{
Simulation Research on EGR Reducing NOx Emission of Diesel Engine
}

\author{
Zhu Jian, Ren Hongjuan, Luo Yiping \\ College of Automobile Engineering, Shanghai University of Engineering Science, Shanghai, P.R. China \\ Email address: \\ 371754791@qq.com (Zhu Jian), 122587984@qq.com (Ren Hongjuan), Lyp777@sina.com (Luo Yiping)
}

To cite this article:

Zhu Jian, Ren Hongjuan, Luo Yiping. Simulation Research on EGR Reducing NOX Emission of Diesel Engine. International Journal of Energy and Power Engineering. Vol. 4, No. 5, 2015, pp. 275-279. doi: 10.11648/j.ijepe.20150405.16

\begin{abstract}
The model of diesel engine and its EGR model were established in the AVL BOOST. The model's validity was verified by comparing with the data of engine bench test. The working conditions selected were $25 \%, 50 \%, 75 \%$ and $100 \%$ load under rated speed. Simulation results show that with the augment of the $\mathrm{EGR}$ rate, $\mathrm{NO}_{\mathrm{X}}$ emissions decreased. When the opening degree of the EGR change from 0 to $100 \%$, the $\mathrm{NO}_{\mathrm{X}}$ of each working conditions decrease $46.23 \%, 42.2 \%, 33.97 \%$ and $32.3 \%$ respectively. At the same time, with the EGR valve opening increase, the reduction of $\mathrm{NO}_{\mathrm{x}}$ is extremely significant.
\end{abstract}

Keywords: EGR, AVL BOOST, $\mathrm{NO}_{\mathrm{x}}$, Simulation

\section{Introduction}

The $\mathrm{NO}_{\mathrm{X}}$ emissions of diesel engine has been polluted environment and harmed human health ${ }^{[1-2]}$. EGR technology, as a kind of internal purification measure, has been widely used in diesel engine ${ }^{[3-4]}$. Domestic and foreign scholars have carried out extensive research on EGR technology to reduce $\mathrm{NO}_{\mathrm{X}}$ emissions of diesel engine. Zhang Quanchang et al studied the influence of the exhaust gas recirculation on the $\mathrm{NO}_{\mathrm{X}}$ and the particle of the diesel engine, the results showed that with the increased of EGR rate, the percentage of NO was decreased firstly, and then it was increased ${ }^{[5]}$. Daniel W. Dickey et al were according to the experimental acquired that the $\mathrm{NO}_{\mathrm{X}}$ emission reduced more than $50 \%$ when the EGR rate was $15 \%{ }^{[6]}$. Yang Shuai et al used BOOST to establish a model of the one-dimensional working model of the turbocharged direct injection diesel engine with EGR system, the simulation results showed that the air fuel ratio, cylinder pressure, cylinder temperature and exhaust temperature of the diesel engine were decreased after using EGR ${ }^{[7]}$. Mattarelli E et al established a computational model for the engine cycle simulation at full load by using the WAVE code, the simulation results showed that the EGR rate played an important role in reduction of $\mathrm{NO}_{\mathrm{X}}$ emission ${ }^{[8]}$. Zhao Lianhang et al used AVL BOOST software to build the model of the EGR system of one heavy diesel machine, and studied different fuel proportion and EGR rate double factors influenced the engine combustion and nitrogen oxide emissions. The results showed that when the EGR rate increased, the nitrogen oxide emissions decreased ${ }^{[9]}$. Wang Yingying et al used GT-POWER software to build the model of diesel engine and the corresponding EGR system, and analyzed the effect of EGR rate on the performance of the whole diesel engine. The research shows that under different working conditions, the EGR rate could effectively reduce the nitrogen oxides emissions ${ }^{[10]}$.

Although there were a lot of experiments and simulations on EGR to reduce the $\mathrm{NO}_{\mathrm{X}}$ emissions, it was necessary to study the effect of different EGR ratio on engine performance under different loads. In this paper, the diesel engine and its EGR model were built by BOOST software. Through adjusted the valve $\mathrm{R}$ to control EGR rate and selected a number of operating load of engine, and studied the effect of different EGR valve on the engine performance, and provided more basis for analyzing EGR reducing $\mathrm{NO}_{\mathrm{X}}$ emissions.

\section{The Simulation of EGR System}

\subsection{The Model of EGR System}

The research object of this article was heavy type diesel engine, this diesel engine's specific technical parameters were shown in Tab. 1.

The engine combustion process has always followed the law of the conservation of energy and mass, so it could be closely relate to the whole cylinder by the energy conservation equation, the mass conservation equation and the gas state equation. Engine cylinder heat changes included the work by piston, the heat generated by burning fuel, wall heat loss and enthalpy flow caused by leakage. By the first law of thermodynamics could get the following formula: 


$$
\frac{d(m u)}{d \varphi}=-p \frac{d V_{s}}{d \varphi}+\frac{d Q_{B}}{d \varphi}-\sum \frac{d Q w}{d \varphi}-h_{B B} \frac{d m_{B B}}{d \varphi}
$$

Where $\mathrm{m}$ was mass of mixed gas in cylinder, $\mathrm{kg}$; $\mathrm{u}$ was internal energy in cylinder, $\mathrm{kJ} / \mathrm{kg} \cdot \mathrm{mol} ; \mathrm{p}$ was pressure of mixed gas in cylinder, $\mathrm{MPa} ; V_{s}$ was cylinder working volume, $\mathrm{L} ; Q_{B}$ was fuel burning heat, $\mathrm{kJ} ; Q_{w}$ was heat lofss of system boundary, $\mathrm{kJ} ; \varphi$ was crank angle, $C A ; h_{B B}$ was enthalpy value of leakage, $\mathrm{kJ} / \mathrm{kg} \cdot \mathrm{mol}$.

Tab. 1. Main structural parameters and operation parameters of diesel engine.

\begin{tabular}{llll}
\hline Form & $\begin{array}{l}\text { Four stroke, turbocharged } \\
\text { inter-cooled, direct injection }\end{array}$ & Inlet valve opening(CA) & Before Top Dead Center20 ${ }^{\circ} \mathrm{C}$ \\
\hline Rated power(kW) & 276 & Inlet valve closed(CA) & After Bottom Dead Center34 ${ }^{\circ} \mathrm{C}$ \\
Rated speed(rpm) & 2100 & exhaust valve opening(CA) & Before Bottom Dead Center49 ${ }^{\circ} \mathrm{C}$ \\
Bore/trip $(\mathrm{mm} / \mathrm{mm})$ & $126 / 155$ & exhaust valve closed(CA) & After Top Dead Center21 ${ }^{\circ}$ \\
Compression ratio & $17: 1$ & displacement(L) & $11.596 \mathrm{~L}$ \\
Ignition sequence & $1-5-3-6-2-4$ & Each cylinder valve number & 4 \\
\hline
\end{tabular}

The equation of gas exchange process could be determined by the law of thermodynamics, and the quality changed in the cylinder can be obtained by the total quality of the flow:

$$
\frac{d m}{d \varphi}=\frac{d m_{B}}{d \varphi}+\frac{d m_{s}}{d \varphi}-\frac{d m_{e}}{d \varphi}
$$

Where $m_{B}$ was mass of fuel in the cylinder, $\mathrm{kg} ; m_{s}$ was mass of gas injected cylinder, $\mathrm{kg} ; m_{c}$ was mass of gas expelled from cylinder, $\mathrm{kg}$.

Gas state equation:

$$
p V_{S}=m R T
$$

Where $\mathrm{R}$ was gas constant.

The equation of the thermodynamic process of the cylinder of diesel engine could be transformed from above equation:

$$
\frac{d T}{d \varphi}=\frac{1}{m\left(\frac{\partial u}{\partial T}+\frac{\partial u}{\partial p} \frac{p}{T}\right)}\left[\frac{d Q}{d \varphi}\left(1-\frac{u+\frac{\partial u}{\partial p} p}{H_{u}}\right)-\frac{d Q_{w}}{d \varphi}-\frac{d m_{B B}}{d \varphi}\left(h_{B B}-u-p \frac{\partial u}{\partial p}\right)-m \frac{\partial u}{\partial \lambda} \frac{d \lambda}{d \varphi}-p \frac{d V}{d \varphi}\left(1-\frac{\partial u}{\partial p} \frac{m}{V_{S}}\right)\right]
$$

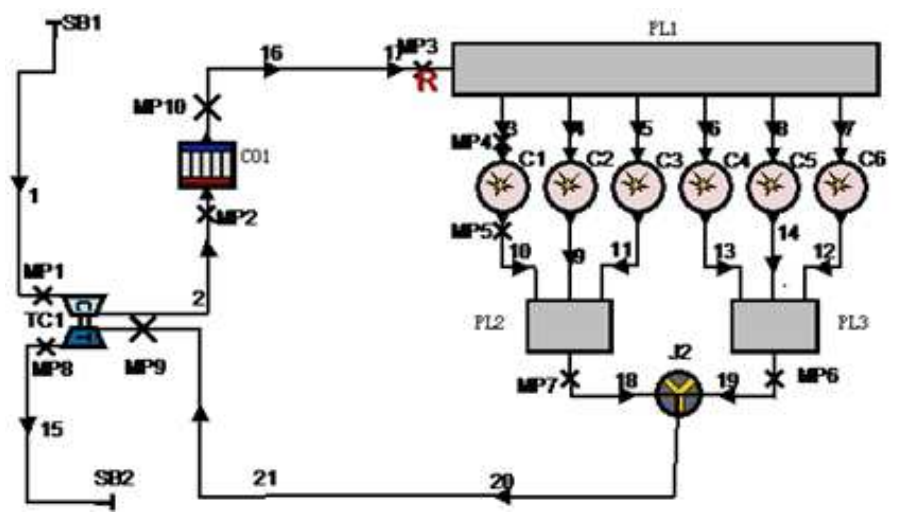

Fig. 1. The model of diesel engine.

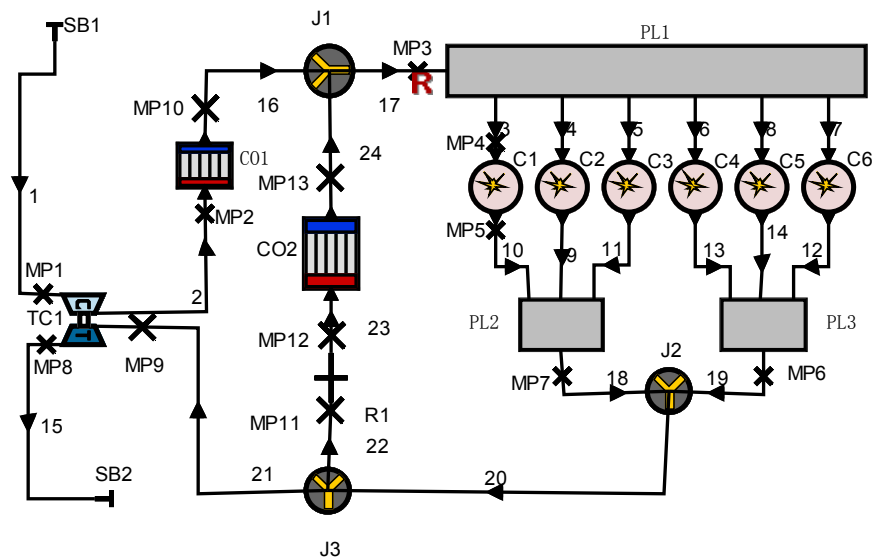

Fig. 2. The model of EGR system. 
In the AVL BOOST software system, the simulation model of diesel engine and its EGR system were established. They were shown in Fig.1 and Fig.2. Modules used in this model include the system boundary, pipes, coolers, turbocharger, volume cavity, cylinder, etc. A large number of measurement points in the pipeline were defined, and these points setting could not affect the characteristics of flow. The fluid temperature, pressure, flow rate and other key parameters in the simulation model obtained through these points.

In the model: SB1、SB2 stood for the system boundary - the inlet and exhaust environment; TC1 stood for exhaust gas turbo; CO1、CO2 stood for intercooler; PL1 stands for inlet manifold; PL2、PL3 stood for exhaust manifold;C1-C6 stood for cylinder; J1、J2、J3 stood for pipeline connection point; R1 stood for pipe valve (EGR valve); 1-24 stood for the system connection line; MP1-MP13 stood for measurement point.

\subsection{The Parameter Setting for Model of EGR System}

In simulation process, the parameters setting for the model directly affected the accuracy of the whole system. In order to ensure the accuracy of the model parameters, the inputting of boundary conditions were based on the test. The parameters included structural parameters and thermodynamic parameters.

Structural parameters included the geometric sizes of the gas flow pipeline, the geometry size of cylinder combustion chamber and the size of cooler etc. The friction coefficient of the pipe wall was determined by the nature of the pipeline material. At the same time we also need to defined the flow coefficient of the pipeline which determined by the recommend value of the software and pipeline structure.

For a cylinder, the simulation calculation could not consider the flow characteristics of gas mixture in cylinder, only the heat engineering were analysis and calculation, and based on the combustion characteristics and the computational requirements. In this paper, the combustion model used MCC model ${ }^{[11]}$. MCC (Mixing Controlled Combustion) model as a quasi-dimensional combustion model has greater advantages compared with zero dimensional combustion model,

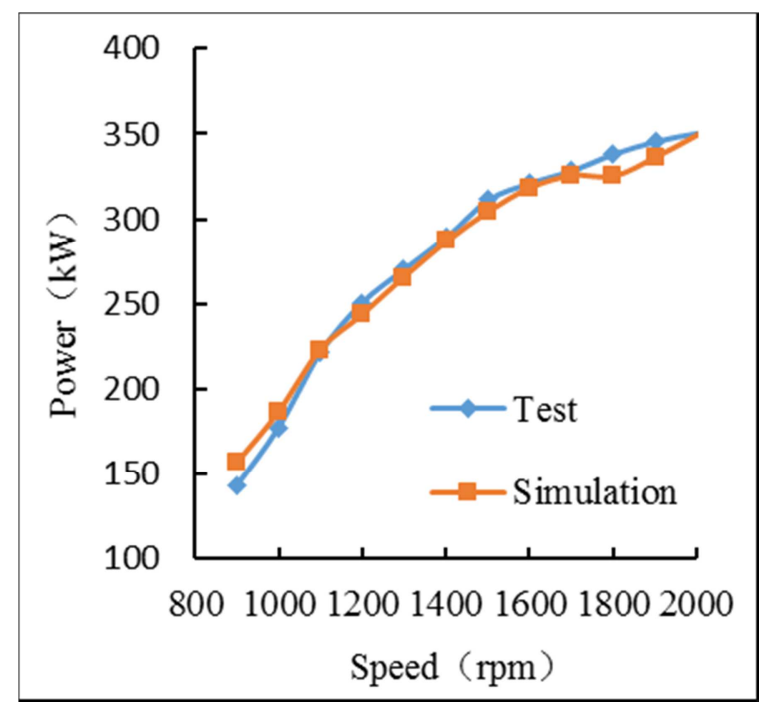

(a) Power especially in the study of $\mathrm{NO}_{\mathrm{X}}$ emissions. We need to input the nozzle number, diameter, flow coefficient and fuel injection law of the simulation engine, in order to calculate the fuel jet velocity and jet kinetic energy.

$$
\begin{aligned}
& \frac{d_{Q}}{d_{\varphi}}=C_{\text {mod }} f_{1}\left(M_{F}, Q\right) f_{2}(K, V) \\
& f_{1}\left(M_{F}, Q\right)=M_{F} \frac{Q}{L C V} \\
& f_{2}(K, V)=\exp \left(C_{\text {rate }} \frac{\sqrt{K}}{\sqrt[3]{V}}\right)
\end{aligned}
$$

where $C_{\text {mod }}$ is the model parameters, $\mathrm{kJ} / \mathrm{kg} /{ }^{\circ} \mathrm{CA} ; \mathrm{V}$ is the instantaneous cylinder volume, $\mathrm{m}^{3} ; C_{\text {mod }}$ is the constant Hybrid rates; $\varphi$ is the Crank Angle, ${ }^{\circ} \mathrm{CA} ; \mathrm{K}$ is the turbulent kinetic energy density, $m^{2} / s^{2} ; M_{F}$ is the jet fuel quality, $\mathrm{kg} ; \mathrm{LCV}$ is the low calorific value, $\mathrm{kJ} / \mathrm{kg} ; \mathrm{Q}$ is the accumulation of heat release, $\mathrm{kJ}$.

\subsection{The Calibration and Verification of Model of EGR System}

The calculation model of diesel engine was established after the parameters set and many times calibration, and simulation results under the requirements condition of diesel engine obtained by AVL BOOST calculation program. The simulation results need to compare with the test data, and the specific validation indexes were the effective power, torque, fuel consumption rate and burst pressure.

Fig. 3 showed the external characteristic curve of the diesel engine. It concluded that the simulation values of the effective power, torque, fuel consumption rate and the burst pressure of the diesel engine could better match with the actually measured values, and the error values were within 5\% which met the requirements of simulation calculation.

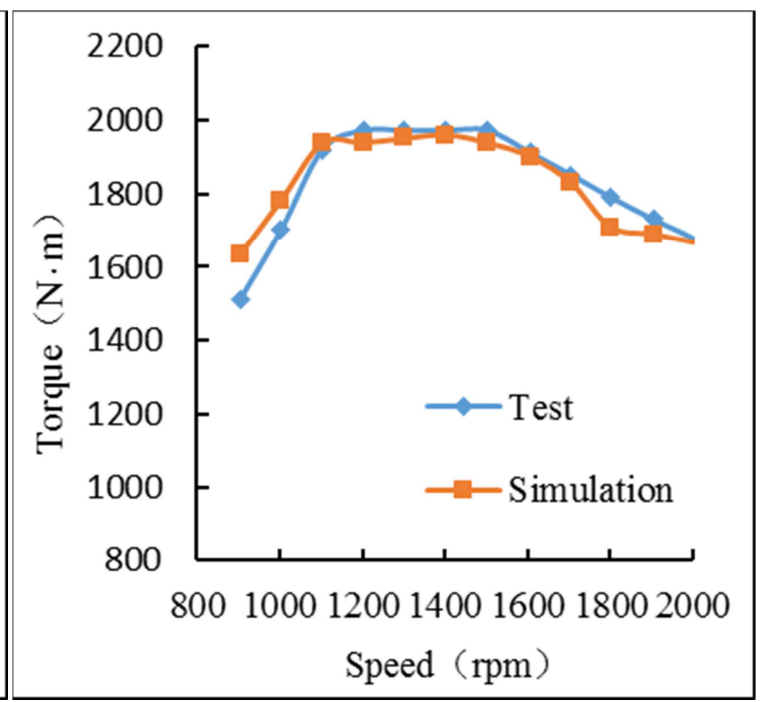

(b) Torque 


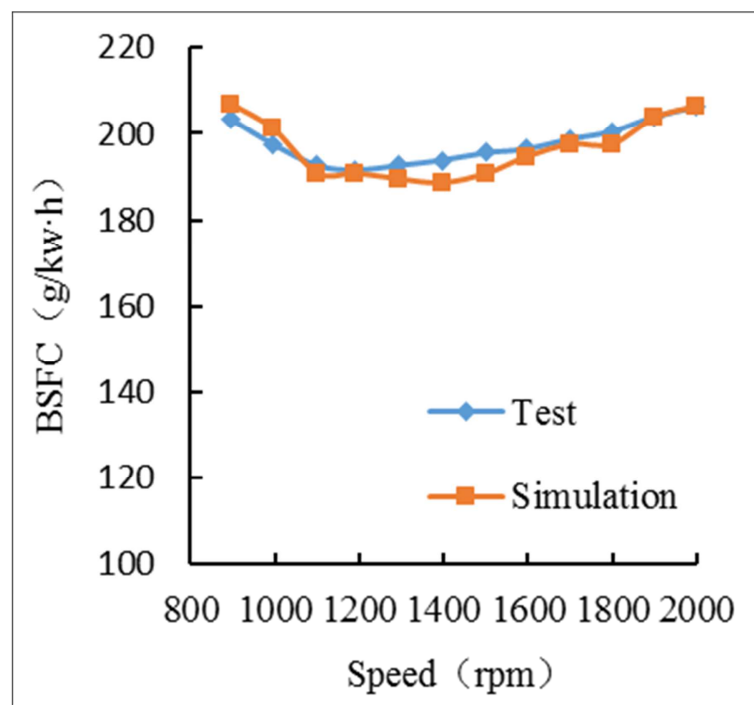

(c) $B S F C$

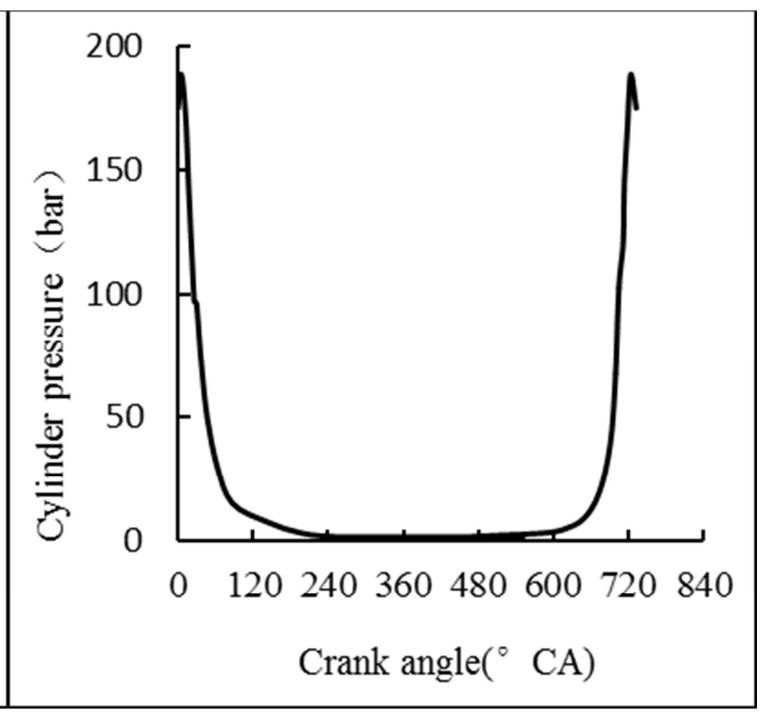

(d) Cylinder pressure

Fig. 3. The curve of external characteristic.

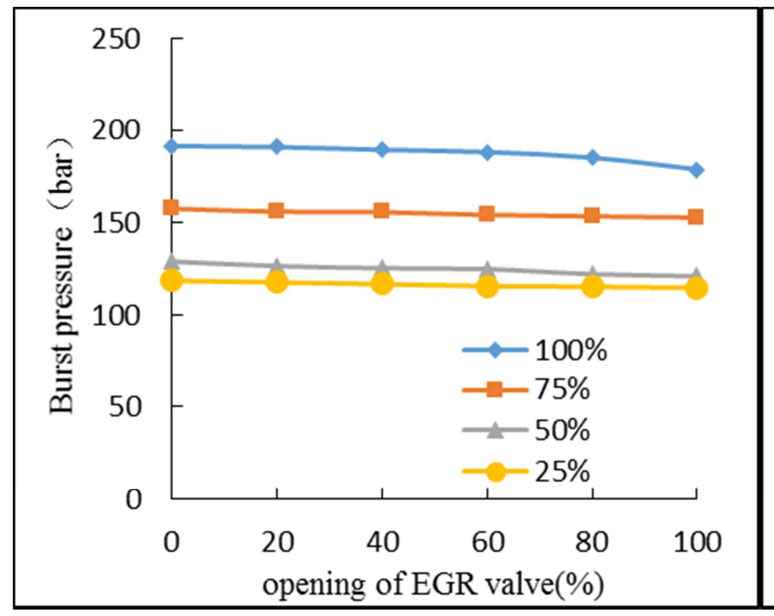

(a) Variation of BP with opening of EGR valve

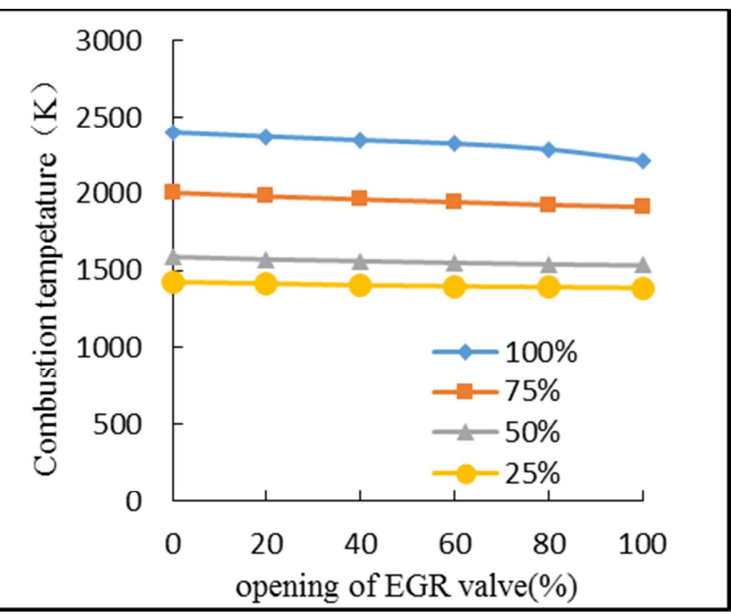

(b) Variation of CT with opening of EGR valve

Fig. 4. Engine performance changed with the opening of EGR valve.

\section{The Influence of the EGR System on Exhaust Emissions of Diesel Engine}

\subsection{The Impact of the EGR Opening on Engine Performance}

Through the test and relevant literature, it was known that when the EGR rate was small, it could not only to ensure the engine power loss was smaller, but also greatly reduced nitrogen oxide emissions. When the EGR rate was large, the exhaust gas in the intake lead to limit lean combustion resulted in severe vibrations generated in engine. These vibrations were not conducive to the normal work of the engine ${ }^{[12]}$.

Based on the above reasons, and the EGR valve was positive correlation with the EGR rate. The EGR valve was controlled within $0 \sim 100 \%$, which can not only ensure the performance of the engine, but also can achieve the purpose of reducing the nitrogen oxide.

The working conditions selected were $25 \%, 50 \%, 75 \%$ and $100 \%$ load under rated speed, and the opening of EGR valve in the model was regulated in order to study the characteristics of engine performance under different EGR rate. Calculation results were shown in Fig. 4.

By the Fig. 4, the maximum explosion pressure and the combustion temperature of the cylinder decreased by the improvement of the opening of EGR valve, but the reduction range was small. The maximum burst pressure of the cylinder was reduced 12.61 bar at $100 \%$ load, the decrease amplitude was $6.5 \%$, the maximum combustion temperature in the cylinder decreased $183 \mathrm{~K}$ at $100 \%$ load, the decrease amplitude was $7.6 \%$; the other operating conditions were also reduced, but the reduction amplitude was little. The main reason was that with the using of EGR, some of the waste gas enters into the intake and mixed with fresh air. Because of the high gas temperature and a large of chemically inert gas $-\mathrm{CO}_{2}$ and $\mathrm{H}_{2} \mathrm{O}$, thus the composition and properties of the mixture gas were changed $^{[13]}$.

\subsection{The Impact of the EGR Opening on $\mathrm{NO}_{X}$ Emissions}

Through controlled the opening of EGR valve, the curve of $\mathrm{NO}_{\mathrm{X}}$ emissions were shown in Fig. 5. 


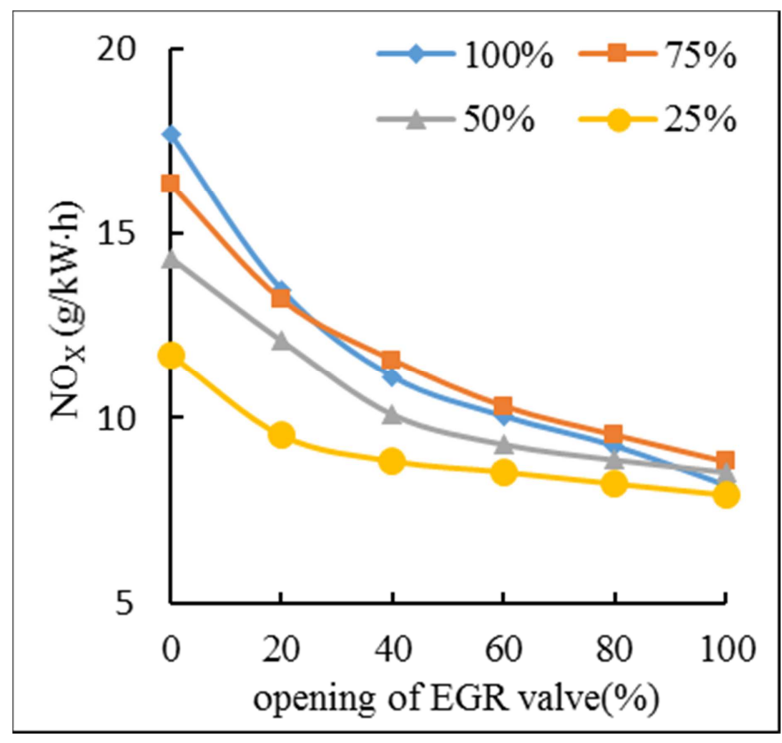

Fig. 5. Curve of $\mathrm{NO}_{X}$ emission.

By Fig. 5 showed, with the increased of EGR rate, $\mathrm{NO}_{\mathrm{X}}$ emissions decreased, when the opening of the EGR changed from 0 to $100 \%$, the $\mathrm{NO}_{\mathrm{X}}$ respectively decreased 9.5 $\mathrm{g} / \mathrm{kW} \cdot \mathrm{h}, 7.46 \mathrm{~g} / \mathrm{kW} \cdot \mathrm{h}, 5.8 \mathrm{~g} / \mathrm{kW} \cdot \mathrm{h}, 3.78 \mathrm{~g} / \mathrm{kW} \cdot \mathrm{h}$ under four working conditions. The reduction rates were $46.23 \%, 42.2 \%, 33.97 \%$ and $32.3 \%$. Mainly due to the using of EGR system, the burning process of fuel delayed, the maximum explosion pressure and the combustion temperature in the cylinder reduced. The $\mathrm{NO}_{\mathrm{X}}$ decreased in the cylinder due to the reduction of temperature, pressure, and oxygen concentrated ${ }^{[14]}$. Under the high load, with the increased of the opening of EGR valve, the reduction of $\mathrm{NO}_{\mathrm{X}}$ was very significant.

\section{Conclusion}

(1) The model of EGR system in this paper was verified by comparing with the data of engine bench test, and the error values were within $5 \%$ which met the requirements of simulation calculation.

(2) The maximum explosion pressure and the combustion temperature of the cylinder decreased by the improvement of the opening of EGR valve. The maximum burst pressure of the cylinder was reduced 12.61 bar at $100 \%$ load; the maximum combustion temperature in the cylinder decreased $183 \mathrm{~K}$ at $100 \%$ load, the reduction amplitude was $7.6 \%$. Because of the EGR made some of the waste gas enters into the intake.

(3) When the opening of the EGR valve was changed from 0 to $100 \%$, the $\mathrm{NO}_{\mathrm{X}}$ emissions decreased respectively 9.5 $g / k W \cdot h, 7.46 \mathrm{~g} / \mathrm{kW} \cdot h, 5.8 \mathrm{~g} / \mathrm{kW} \cdot \mathrm{h}, 3.78 \mathrm{~g} / \mathrm{kW} \cdot \mathrm{h}$ under $100 \%, 75 \%, 50 \%, 25 \%$ load, and the maximum explosion pressure and the combustion temperature in the cylinder reduced because of EGR made the burning process of fuel delayed, the maximum explosion pressure and the combustion temperature in the cylinder reduced.

\section{References}

[1] Rao Peng Hui, Wu Da Wei. The survey of distribution of exhaust pollution of motor vehicle [J]. Journal of resource saving and environmental protection, 2013 (5): 58-62.

[2] Xu Guang Jun. The formation mechanism and purifying measures for main pollutants of diesel engine [J]. Journal of liaoning transportation science and technology. 2005 (12): 75-77.

[3] R. S. G. Baert, D. E. Bechman, Efficient EGR technology for future HD diesel engine emission targets, SAE paper 1999-01-0837.

[4] Toshihiko, Hidetoshi. Electrically operated EGR value that reduces automotive emissions. Mitsubishi Electric Advance, 1999 (86): 20-24.

[5] Zhang Quanchang, Rao Mingfa, Zheng Zunqing, et al. Experimental study on the influence of exhaust gas recirculation on $\mathrm{NOx}$ and particulate emission of diesel engine[J]. Journal of internal combustion engine, 201230 (4): 310-315.

[6] Daniel W. Dickey, Thomas W. Ryan III, NOx Control in Heavy-Duty Diesel Engine-What is the limit?, SAE 980174, 1998.

[7] Yang Shuai, Zhou Yi, ZouRenling, et al. The one dimensional simulation of EGR influence on the working process of diesel engine [J]. Journal of agricultural machinery, 2008(39):11-14.

[8] Mattarelli E, Bianchi G M, Ivaldi D. Experimental and numerical investigation on the EGR system of a new automotive diesel engine[C]. SAE Paper 2000-01-0224, 2000.

[9] Zhao Lianhang. Simulation research on the work process of 4L20 diesel engine and characteristics of NOx emission [D]. Dalian Maritime University, 2012.

[10] Wang Yingying, Zhou Bin. Modeling and Simulation of $8 \mathrm{~V} 240 \mathrm{ZJ}$ diesel engine $[\mathrm{J}]$. Internal combustion engine and power plant, 2012, (3): 37-40.

[11] AVL BOOST User Guide Version [M]. Graz, Austria: AVL Company, 2008.

[12] ZhouQi. The research for EGR system of automotive engine [D]. Tongji University, 2002.

[13] Shen Zhaojie. Analysis of the combustion process of diesel engine and the research on the layer of EGR [D]. Jilin Univresity, 2013.

[14] Wang Xu, Yao Ming Fa, Zheng Zun Qing. The study on influence of multiple injection and EGR coupling controlled for the performance and emissions of the engine [J]. Journal of internal combustion engine, 2010 (01): 103-108. 